Bangladesh Journal of Anatomy January 2009, Vol. 7 No. 1 pp. 10-13

\title{
Anthropometric Measurements of the hand length and their correlation with the Stature of Bengali adult Muslim females
}

\author{
Syeda Zamila Hasan Laila ${ }^{1}$, Roxana Ferdousi ${ }^{2}$, ABM Nurunnobi ${ }^{3}$, ATM Shafiqul Islam ${ }^{4}$, \\ Syeda Zamila Hosen Holy ${ }^{5}$, Farzana Yesmin ${ }^{6}$
}

\begin{abstract}
Context: Stature or body height is one of the most important and useful anthropometric parameter that determine the physical identity of an individual. The study was done to estimate stature from the hand length on one hundred and fifty Bengali adult Muslim females.
\end{abstract}

Study design: descriptive cross sectional study.

Place of Study: department of Anatomy, BSMMU, Dhaka.

Material: One hundred and fifty Bengali adult Muslim female was collected from BSMMU \& some urban region of Dhaka.

Method: Measurement of stature and hand length of right and left side was taken with a standard anthropometer and a slide caliper respectively.

Result: The present study showed significant $(p<0.001)$ positive correlation between the stature and hand lengths.

Key words: anthrpometric measurement, hand length.

Introduction:

Stature is natural heights of a person in an upright position. This can be estimated from hand length ${ }^{1}$. The hand lengths can be used as a basis for estimating age- related loss in stature and as an alternative measure to stature when stature cannot be measured directly due to deformity like kyphosis, lordosis and scoliosis, contracture or missing legs. In these cases the original stature of those people can be estimated by multiplying the dimension of hand lengths of those sexes or ethnic groups with respective multiplication factor. The multiplication factor can be obtained by making ratio of the stature to the hand lengths.

1. Assistant Professor, Anatomy Department, Northern International Medical College

2. Professor, Anatomy Department, Anwar Khan Modern MedicalCollege

3. OSD DG health, Deputed in NICVD

4. Program Executive, Social Marketing Company.

5. Lecturer, Anatomy Department, Anwar Khan Modern Medical College.

6. M.Phil, Physiology $3^{\text {rd }}$ part BSMMU.

Correspondence: Dr. Syeda Zamila Hasan Laila
Materials and methods: The study was a predominantly descriptive cross sectional study with some analytical components. It was done on one hundred and fifty Bengali adult Muslim females, 2530 years approximate by age. ${ }^{2}$ Measurement of the stature was taken with a standard anthropometer. The stature was measured as the vertical distance from the vertex to the floor. Measurement was taken by making the subject stand erect on a horizontal resting plane bare footed having the palms of the hands turned inwards and the fingers pointing downwards. Then, the movable piece of the anthropometer was brought in contact with the vertex in the mid sagital plane. The length of each hand was measured using a sliding caliper. The subject was asked to place her hand on a table with the fingers together and thumb abducted. The measurement was taken from the level of tip of the most distal point on the styloid process of the radius to the tip of the middle finger ${ }^{3}$. The measurements were recorded in centimeters to the nearest 0.1 $\mathrm{cm}^{4}$. 


\section{Formula for measurement of any length by slide caliper}

Length $=$ Reading of the main scale + Vernier coincidence $x$ Vernier constant + Mechanical error

\section{Results:}

The present study showed positive correlation ( $p$ value $<0.001$ ) between the stature and hand lengths.
The mean stature and mean hand length of the right and left were $156.02( \pm 6.13) \mathrm{cm}, 16.39( \pm 0.79)$ $\mathrm{cm}$ and $16.34( \pm 0.80) \mathrm{cm}$ respectively. The stature and other measurements are shown in Table 1.1 along with the multiplication factors used to estimate the stature from these measurements. The table also shows the correlation coefficients ( $r$ ) and $p$ values to reveal the relationships between specific measurements and stature.

Table 1.1

Stature and measurements of the hand length, the multiplication factors for estimating stature from the hand length measurements and correlation of these measurements with stature.

\begin{tabular}{lccccccc}
\hline Variable & Range $(\mathrm{cm})$ & Mean $(\mathrm{cm})$ & \pm & $\mathrm{SD}$ & $\begin{array}{c}\text { Mean } \\
\text { multiplication } \\
\text { factor* }\end{array}$ & $\begin{array}{c}\text { Correlation of hand } \\
\text { length measurements } \\
\text { with stature }\end{array}$ \\
\hline Stature & $145.45-177.50$ & 156.02 & \pm 6.13 & & & $\mathrm{p}$ \\
Right hand length & $14.10-18.11$ & 16.39 & \pm 0.79 & 9.51 & 0.68 & $0.001(\mathrm{~S})$ \\
Left hand length & $13.82-18.10$ & 16.34 & \pm 0.80 & 9.28 & 0.68 & \\
\hline
\end{tabular}

$n=150$ S: Significant $\quad r$ : correlation coefficient $p$ : probability $(p<0.05$ was considered as significant) Each multiplication factor is the ratio of the stature to the respective physical measurements

Table 1.2

Comparison of the measured stature with the stature estimated from hand length of the right and left side

\begin{tabular}{lccccc}
\hline $\begin{array}{l}\text { Measurement from } \\
\text { which the stature } \\
\text { was estimated }\end{array}$ & \multicolumn{2}{c}{ Estimated Stature (cm) } & & $\begin{array}{l}\text { P value representing the } \\
\text { significance of difference } \\
\text { between the measured stature } \\
\text { and the estimated stature }\end{array}$ \\
\hline & Range & Mean & & & \\
Right hand length & $133.24-172.23$ & 155.87 & \pm & 7.52 & 0.734 (NS) \\
Left hand length & $128.25-167.97$ & 151.66 & \pm & 7.44 & 0.747 (NS) \\
\hline
\end{tabular}

The measured stature ranged from 145.45 to $177.50 \mathrm{~cm}$ with a mean $( \pm S D)$ of $156.02( \pm 6.3) \mathrm{cm}$. $\mathrm{n}=150 \mathrm{NS}=$ Non-significant.

In the present study there were a significant $(p<0.001)$ positive correlation between the stature and the length of the right and left hand (Figures 1.01, 1.02, 1.03, 1.04). 


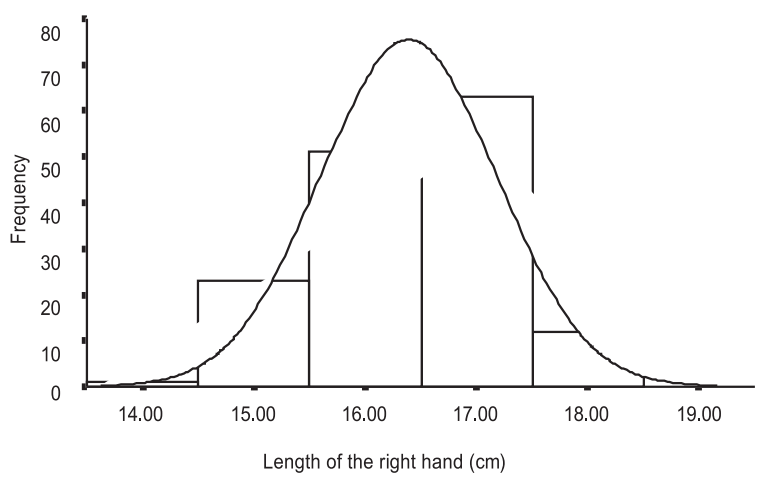

Fig1.01 Frequency curve showing frequency distribution of the length of the right hand of the Bengali adult Muslim females ( $n=150$ ).

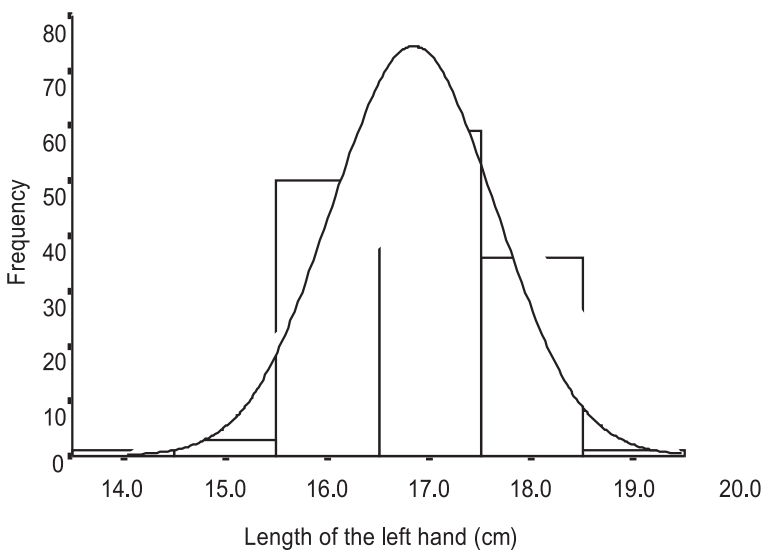

Fig1.02 Frequency curve showing frequency distribution of the length of the left hand of the Bengali adult Muslim females ( $n=150)$.

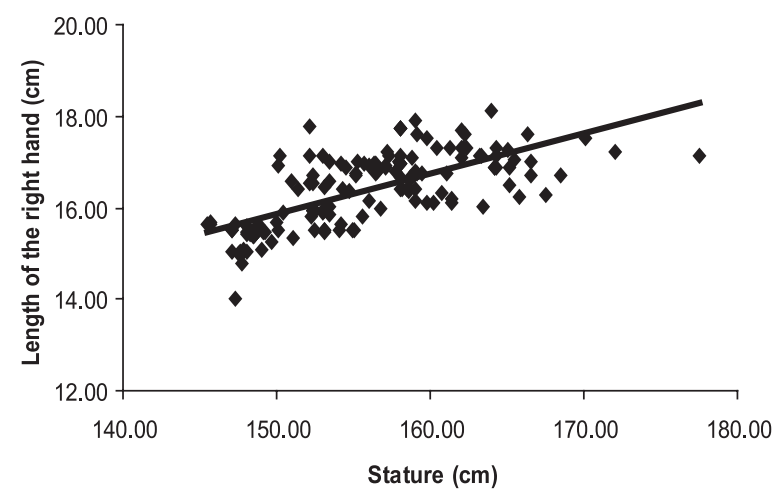

Fig 1.03 Scatter diagram with regression analysis showing significant $(p<0.001)$ positive correlation $(r=0.68)$ between the stature and the length of the right hand of the Bengali adult Muslim females $(n=150)$.

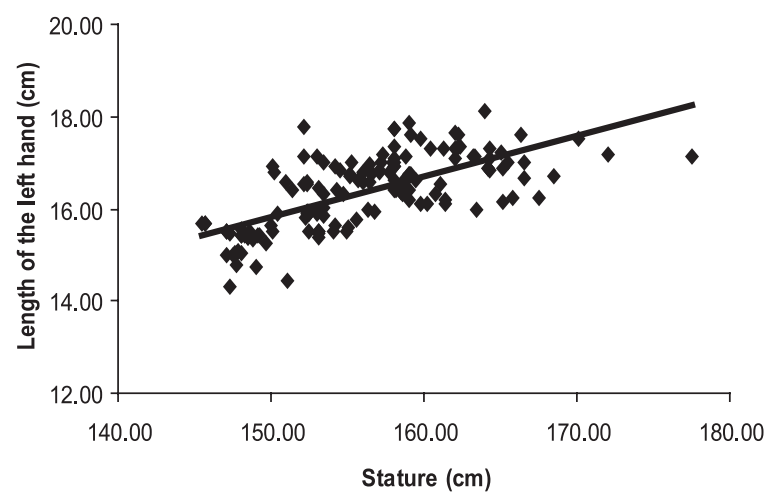

Fig1.04 Scatter diagram with regression analysis showing significant $(p<0.001)$ positive correlation $(r=0.68)$ between the stature and the length of the left hand of the Bengali adult Muslim female $(n=150)$.

\section{Discussion:}

In the present study the mean stature was $156.02( \pm 6.13) \mathrm{cm}$ and the mean length of the right and left hand was $16.39( \pm 0.79) \mathrm{cm}$ and16.34 $( \pm 0.80)$ $\mathrm{cm}$. respectively. The multiplication factor of right side was 9.51 and left side was 9.28 From the present study we found some multiplication factor. Multiplying these multiplication factors with the hand length we found some estimated statures which were correlate with the measured stature.All the measurements in this study were a positive as well as a statistically significant correlation with the stature ${ }^{5}$.

\section{Conclusion:}

From the present study we found some multiplication factors which were helpful for Bengali adult Muslim females for estimation of stature from respective hand lengths. That may be helpful for those who work in this area especially in the various medical disciplines, anthropologists, and security experts of Bangladesh.

\section{References}

1. Jasuja OP, Singh G. Estimation of stature from hand and phalange length. Journal of Indian Association of Forensic Medicine, 2004; 26(3): 100-106. 
2. Athwale MC. Anthropological study of height of forearm bones. American Journal of Physical Anthropology, 1963; 21: 105-121.

3. Jasuja OP, Singh G. Estimation of stature from hand and phalange length. Journal of Indian Association of Forensic Medicine, 2004; 26(3): 100-106.
4. Joshi NB, Patel MP, Regression equation of height on ulnar length. Indian Journal of Medical Research, 1964; 52 (10): 1088-1091.

5. Saxena SK. A study of correlation and estimation of stature from hand length, hand breadth and sole length. Anthrop Anz., 1984; 42 (4): 271-276. 